\title{
PARP Inhibitors for Recurrent Ovarian Carcinoma: Current Treatment Options and Future Perspectives
}

\author{
PARP-Inhibitoren beim rezidivierenden Ovarialkarzinom, \\ aktuelle Therapieoptionen und zukünftige Entwicklungen
}

Authors

Affiliations
J. Sehouli ${ }^{1}$, E. I. Braicu ${ }^{2}$, R. Chekerov ${ }^{2}$

1 Universitätsklinikum Berlin Charité, Klinik für Gynäkologie, Charté Comprehensive Cancer Center (CCCC), Berlin

${ }^{2}$ Universitätsklinikum Berlin Charité, Campus Virchow-Klinikum, Klinik für Gynäkologie, Charté Comprehensive Cancer

Center (CCCC), Berlin

\begin{abstract}
Key words
- ovarian cancer

- BRCA

- molecular pathway

- PARP inhibitors

Schlüsselwörter

- Ovarialkarzinom

- BRCA

- Signaltransduktionsweg

- PARP-Inhibitor
\end{abstract}

Deutsche Version unter: www.thieme-connect.de/ ejournals/gebfra

\section{Abstract \\ $\nabla$}

More than simply a promising management option, PARP inhibitors can be regarded as a milestone in the development of personalised treatment of recurrent ovarian carcinoma. Their mechanism of action, known as "synthetic lethality", is dependent on functional differences of the DNA repair mechanisms of healthy cells and tumour cells; cells that repair DNA damage less efficiently are particularly sensitive to PARP inhibitors. Olaparib, licensed for use this year, is the beststudied PARP inhibitor used for treatment of high-grade serous ovarian carcinoma (HGSC). The efficacy of PARP inhibitors appears to be increased when used in combination with other treatments.

\section{Zusammenfassung \\ $\nabla$}

PARP-Inhibitoren stellen nicht nur eine sehr vielversprechende Behandlungsmöglichkeit dar, ihre Entwicklung kann zudem als Meilenstein bei der Einführung einer personalisierten Medizin in der Behandlung des rezidivierten Ovarialkarzinoms betrachtet werden. Ihre Wirkungsweise, auch als synthetische Letalität bezeichnet, beruht auf den unterschiedlichen Funktionalitäten der DNA-Reparaturmechanismen bei gesunden und Tumorzellen. Zellen, die eine verminderte Fähigkeit aufweisen, DNA-Schäden effizient zu reparieren, sind besonders sensitiv gegenüber PARP-Inhibitoren. Bei Olaparib handelt es sich um den beim High-grade, serösen Ovarialkarzinom (HGSC) inzwischen am besten untersuchten und seit diesem Jahr zugelassenen PARP-Inhibitor. Die Kombination von PARP-Inhibitoren mit anderen Therapieansätzen scheint die Effektivität der PARPInhibitoren zu steigern.

\section{received 15.6.2015 \\ revised $\quad 16.8 .2015$ \\ accepted 14.9.2015}

Bibliography

Dol http://dx.doi.org/

10.1055/s-0035-1558185

Geburtsh Frauenheilk 2016; 76:

164-169 (c) Georg Thieme

Verlag KG Stuttgart · New York . ISSN 0016-5751

\section{Correspondence}

Dr. med. Radoslav Chekerov Universitätsklinikum Berlin Charité

Campus Virchow-Klinikum Klinik für Gynäkologie

Charité Comprehensive Cancer Center (CCCC)

Augustenburger Platz 1

13353 Berlin

radoslav.chekerov@charite.de

\section{Introduction}

$\nabla$

Ovarian carcinoma is the 5th most common cause of cancer related death in German women and has the highest mortality of all gynaecological cancers [1]. Treatment options have continued to improve in recent years due to both better operative techniques and systemic therapies, however a relative 5-year survival rate of $42 \%$ [1] is still disappointing; most patients have disease recurrence despite radical surgery and platinum/taxane-based chemotherapy [2].

Ovarian carcinoma is usually sporadic with 5 to $10 \%$ being hereditary, mostly with mutations of the BRCA1 and/or BRCA2 genes. Women with a BRCA1 mutation have a $40-55 \%$ lifetime risk of ovarian carcinoma before the age of 70 ; for carriers of BRCA2 mutations the risk is $11-17 \%$ [3]. The clinical course of ovarian carcinoma in the pres- ence of BRCA mutations differs significantly from that with intact $B R C A$. Overall survival is significantly better for carriers of BRCA1 and BRCA2 mutations (for BRCA1: hazard ratio (HR), $0.73 ; 95 \% \mathrm{CI}$, 0.64-0.84; $\mathrm{p}<0.001$; for BRCA2: $\mathrm{HR}, 0.49$; $95 \% \mathrm{CI}$, $0.39-0.61 ; p<0.001$ ) [4]. There is evidence that BRCA associated tumours are particularly sensitive to DNA alkylators and intercalating agents such as the platinum derivatives. Studies of tumour tissue from the TCGA project (the Cancer Genome Atlas http://cancergenome.nih.gov) have shown that mutations of genes involved with DNA repair mechanisms (HRR, homologous recombination repair) are present in about $50 \%$ of high-grade (G2-3) serous ovarian carcinomas (HGSC) [5].

The introduction of PARP inhibitors as a new, targeted intervention has shown clinical benefit in numerous studies of recurrent platinum-sensitive ovarian carcinoma, the greatest benefits ap- 
plying to carriers of BRCA mutations [6]. This article will detail the current status of the PARP inhibitors that have been subjected to clinical trials, and describe their importance in the treatment of recurrent ovarian carcinoma.

Among tumour therapies Poly (ADP-ribose) polymerase (PARP) inhibitors are a drug class known to provide impressive results. Their mechanism of action has largely been described in preclinical studies $[7,8]$. The addition of a PARP inhibitor to treatment regimes for recurrent ovarian carcinoma, consisting of established systemic therapies, appears to provide a definite improvement in disease response. The molecular biological characterisation of tumour tissue as precisely as possible is decisive for treatment success with PARP inhibitors as it enables an individualised treatment strategy.

\section{Background Information on Mechanism of Action and a Description of the Substance Class}

Poly (ADP-ribose) polymerases (PARP) are a family of numerous individual enzymes of which at least 2 (PARP-1 und PARP-2) are involved in repairing damaged DNA $[7,9]$. DNA repair mechanisms play an important roll in the maintenance of genomic integrity and consequently in cell survival. Numerous factors, e.g. metabolic byproducts such as reactive oxygen species, can damage DNA through causing single-strand breaks. Repair of these single-strand breaks usually occurs through base excision repair (BER), a mechanism in which members of the PARP family of enzymes are involved. If repair does not occur or is incomplete, double-strand breaks arise during the next DNA replication. In healthy cells these are repaired by homologous recombination repair (HRR) and the error-prone non-homologous end joining (NHEJ). PARP inhibitors initially prevent the repair of singlestrand breaks by inhibiting BER. In HRR deficient cells, which are characterised by mutations in the BRCA1 and/or BRCA2 genes, effective repair of double-strand breaks is not possible either. It is now known that there are also other genetic/epigenetic errors that can restrict the cell's ability to repair DNA damage efficiently. Repair is then carried out more often by the error-prone NHEJ mechanism resulting in the accumulation of DNA damage that leads to cell death. In addition to inhibiting the BER pathway PARP inhibitors stimulate the NHEJ pathway promoting cell death of HRR deficient cells [10]. The mechanism of action of PARP inhibitors is known as "synthetic lethality"; schematic representation in $\bullet$ Fig. 1.

\section{BRCA and "BRCAness"}

BRCA1 and BRCA2 are classified as tumour suppressor genes. Their gene products are involved in homologous recombination (HR) mediated DNA repair. Patients with BRCA1/2 mutations are at increased risk of various forms of cancer; for ovarian carcinoma the risk is $10-55 \%$. The term "BRCAness" describes characteristics of a sporadic tumour that are usually found in tumours among BRCA1/2 germ line mutation carriers; genetic or epigenetic errors are usually present leading to loss of HR associated DNA repair. Tumour cells that do not have efficient DNA repair mechanisms are particularly sensitive to DNA damaging drugs such as platinum-based chemotherapies. PARP inhibitors are promising for tumour treatment not only in the presence of $B R C A$ mutations but possibly also where there is "BRCAness".

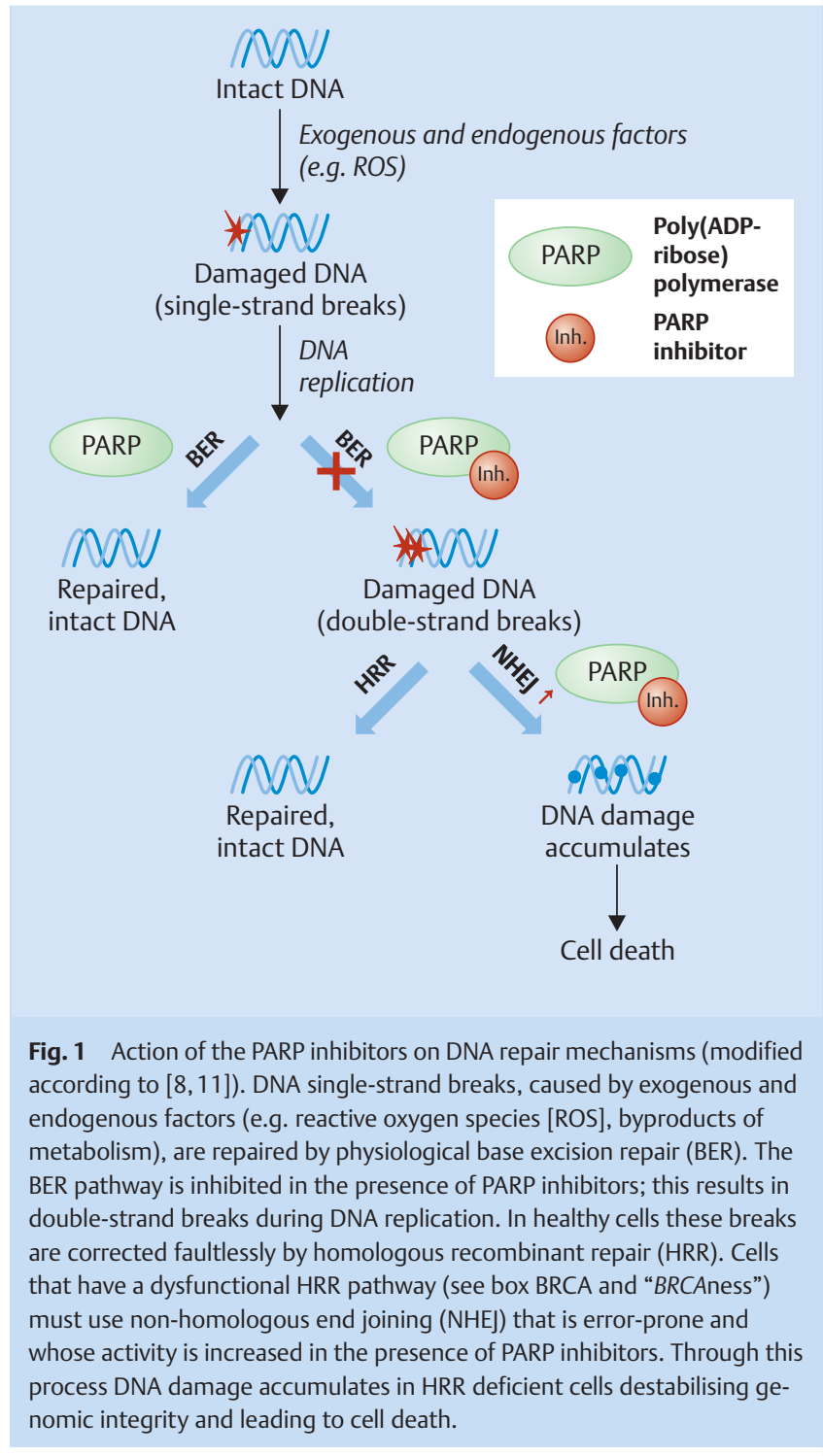

PARP inhibitors block the enzymatic activity of PARP by attaching to the enzyme's active centre and competing with its natural substrate. In addition to their pure enzyme blocking action some PARP inhibitors appear to induce the formation of a PARP-DNA complex that further impairs DNA repair [11].

\section{Clinical Studies in Recurrent Ovarian Carcinoma}

The PARP inhibitors available for tumour treatment today have high potency and specificity. Their efficacy and tolerability in patients with ovarian carcinoma, most often with BRCA1 and/or BRCA2 gene mutations, have been studied in numerous clinical trials. Data from the clinical development of the most promising of the PARP inhibitors will now be detailed. Since its antitumour action is no longer ascribed to PARP inhibition [12], iniparib will not be considered further here.

\section{Olaparib}

Olaparib is currently the best-studied oral PARP inhibitor (PARP1 and PARP-2 blockade) for use in ovarian carcinoma. Numerous phase I and phase II trials have shown its efficacy for BRCA asso- 
Table 1 Pivotal trials on the efficacy olaparib monotherapy.

\begin{tabular}{|c|c|c|c|c|c|}
\hline Study & $\begin{array}{l}\text { Requirements (inclusion } \\
\text { criteria) with respect } \\
\text { to previous treatment }\end{array}$ & $\begin{array}{l}\text { BRCA status and } \\
\text { patient number } \\
\text { in olaparib group }\end{array}$ & Dose & Clinical & \\
\hline Phase I [13] & $\begin{array}{l}\text { No requirement, categorisation } \\
\text { according to platinum resistance } \\
\text { or sensitivity }\end{array}$ & $\begin{array}{l}\text { BRCAm }^{+} \\
\mathrm{n}=50\end{array}$ & $\begin{array}{l}40 \mathrm{mg} \text { daily up to } \\
\text { max. } 600 \mathrm{mg} \text { BID } \\
\text { Dose escalation }\end{array}$ & $\begin{array}{l}\text { CBR } \\
\text { Plat-sens: } 69 \% \\
\text { Plat-res: } 45 \% \\
\text { Plat-refr: } 23 \%\end{array}$ & RD: 28 weeks \\
\hline \multirow[t]{2}{*}{ Phase II [14] } & $\begin{array}{l}\text { At least one previous unsuccessful } \\
\text { chemotherapy }\end{array}$ & $\begin{array}{l}\text { BRCAm }^{+} \\
\mathrm{n}=33\end{array}$ & $400 \mathrm{mg}$ BID & ORR 33\% & RD: 41 weeks \\
\hline & & $\begin{array}{l}\text { BRCAm }^{+} \\
\mathrm{n}=24\end{array}$ & $100 \mathrm{mg}$ BID & ORR 13\% & RD: 38 weeks \\
\hline Phase II [15] & No requirement & $\begin{array}{l}\text { BRCAm }{ }^{+} \\
n=17 \\
\text { BRCAwt } \\
n=46\end{array}$ & $400 \mathrm{mg}$ BID & $\begin{array}{l}\text { ORR } \\
\text { BRCAm : } 41 \% \\
\text { BRCAwt: } 24 \%\end{array}$ & $\begin{array}{l}\text { PFS } \\
\text { BRCAm+: } 7.3 \text { months } \\
\text { BRCAwt: } 6.3 \text { months }\end{array}$ \\
\hline \multirow[t]{2}{*}{ Phase II [16] } & $\begin{array}{l}\text { Recurrence/progression within } \\
12 \text { months of previous platinum- } \\
\text { based therapy }\end{array}$ & $\begin{array}{l}\text { BRCAm }^{+} \\
n=32\end{array}$ & $400 \mathrm{mg}$ BID & ORR: $31 \%$ & PFS: 8.8 months \\
\hline & & $\begin{array}{l}\text { BRCAm }^{+} \\
\mathrm{n}=32\end{array}$ & $200 \mathrm{mg}$ BID & ORR: $25 \%$ & PFS: 6.5 months \\
\hline Phase II [6] & $\begin{array}{l}\text { At least } 2 \text { previous platinum-based } \\
\text { agents, platinum sensitivity }\end{array}$ & $\begin{array}{l}\text { BRCAm }^{+} \\
n=74 \\
\text { BRCAwt } \\
n=57\end{array}$ & $400 \mathrm{mg}$ BID & & $\begin{array}{l}\text { PFS } \\
\text { BRCAm+: } 11.2 \text { months } \\
\text { BRCAwt: } 7.4 \text { months }\end{array}$ \\
\hline
\end{tabular}

BID: twice daily; BRCAm': Mutation in BRCA1/BRCA2; BRCAwt: BRCA Wildtype; CBR: Clinical Benefit Rate; ORR: Overall Response Rate; PFS: Progression-free Survival; RD: Response Duration

ciated ovarian carcinoma and recurrent somatic mutation highgrade serous ovarian carcinoma (data summarised in $\bullet$ Table $\mathbf{1}$ ) [6,13-16]. In a phase I trial, Fong et al. [13] showed that the clinical benefits of olaparib (200 mg twice daily) for BRCA associated malignant epithelial tumours of the ovary, salpinges (fallopian tubes) and peritoneum was significantly greater in platinumsensitive disease (clinical benefit rate [CBR] 69.2\%) compared to platinum-resistant and refractory disease (CBR $45.6 \%$ and $23.1 \%$ respectively). A course of olaparib (400 mg twice daily) [17] increased progression-free survival (PFS) in platinum-sensitive recurrent HGSC measurably. This effect was particularly impressive among women with BRCA-mutation associated tumours (PFS in olaparib group 11.2 months vs. 4.3 months in placebo group) [6]. With data collection still incomplete ( $58 \%$ of events) a statistical difference in overall survival has not yet been shown for olaparib, though a numeric effect is already evident (total study population: HR 0.99 [95\% CI 0.64-1.21]; patients with BRCA mutations: HR 0.73 [95\% CI 0.45-1.17]) [6].

Olaparib monotherapy is generally well tolerated (maximum tolerable dose $400 \mathrm{mg}$ twice daily) [18]. Side effects included gastrointestinal symptoms such as nausea and vomiting, fatigue and mild haematotoxicity. A complete representation of all adverse events therapy is shown in 0 Table 2. Myelodysplastic syndrome and acute myeloid leukaemia occurred in a few cases during olaparib monotherapy, however since these patients had all undergone intensive tumour treatment previously (notably with chemotherapy) there is a degree of doubt as to whether these events were a direct effect of olaparib. The safety and efficacy of olaparib is being tested further in numerous phase III trials both in primary advanced BRCA-associated ovarian carcinoma after platinum-based chemotherapy (SOLO1) and in platinum-sensitive BRCA-associated recurrent ovarian carcinoma after a response to platinum-based chemotherapy (SOLO2, SOLO3).
Olaparib (Lynparza ${ }^{\circledR}$ ) is now available on the market as the first officially licensed PARP inhibitor. After its fast-track licensing by the FDA (1/2015) it was subsequently licensed by the EMA (4/ 2015) as monotherapy for maintenance treatment of platinumsensitive recurrent BRCA-mutation (germ line and/or somatic) high-grade serous epithelial ovarian carcinoma, carcinoma of the salpinges or primary peritoneal carcinoma with clinical response to platinum-based chemotherapy.

\section{Veliparib}

Veliparib (ABT-888) was initially researched in numerous preclinical and pharmacokinetic trials. A pharmacokinetic trial of diverse tumour entities showed an inhibitory effect (veliparib dose $25 \mathrm{mg}$ and $50 \mathrm{mg}$ ) on PARP in tumour tissue and blood samples [19]. Since then numerous phase I trials of veliparib as a drug combination partner for various tumour entities have been conducted (cyclophosphamide [20]; temolozomide [21]; topotecan [22]). Published in March 2014, the provisional findings of a phase II trial involving 52 patients with recurrent or persistent $B R C A$-associated ovarian carcinoma suggest veliparib is potentially effective used as monotherapy [23]. At a veliparib dose of $400 \mathrm{mg}$ twice daily the overall response rate was $26 \%$ with a better response rate for platinum-sensitive disease than platinumresistant disease (35 vs. 20\%). Toxicity of veliparib monotherapy was described as acceptable. Side effects included gastrointestinal symptoms, fatigue and haematological toxicity with a need for dose reduction because of toxicity in $48 \%$ of patients. The efficacy of veliparib for recurrent ovarian carcinoma is currently being tested in numerous phase II trials. Most current phase III trials are focused on combination strategies using veliparib and other chemotherapeutic agents for various solid tumours (breast carcinoma, non-small cell bronchial carcinoma, glioblastoma). 
Table 2 Pivotal trials on the safety of olaparib monotherapy in ovarian carcinoma.

\begin{tabular}{|c|c|c|c|c|}
\hline \multirow[t]{4}{*}{ Trial } & \multirow{4}{*}{$\begin{array}{l}\text { Dose/ } \\
\text { Patient } \\
\text { number }\end{array}$} & \multirow[t]{4}{*}{ Toxicity } & \multirow{4}{*}{$\begin{array}{l}\text { Grade } \\
1-2\end{array}$} & \multirow{4}{*}{$\begin{array}{l}\text { Grade } \\
3-4\end{array}$} \\
\hline & & & & \\
\hline & & & & \\
\hline & & & & \\
\hline \multirow{5}{*}{$\begin{array}{l}\text { Phase II } \\
{[14]}\end{array}$} & $400 \mathrm{mg}$ BID & nausea & $42 \%$ & $6 \%$ \\
\hline & $\mathrm{n}=33$ & fatigue & $30 \%$ & $3 \%$ \\
\hline & & anaemia & $15 \%$ & $3 \%$ \\
\hline & $100 \mathrm{mg}$ BID & nausea & $29 \%$ & $8 \%$ \\
\hline & $\mathrm{n}=24$ & fatigue & $38 \%$ & $0 \%$ \\
\hline \multirow{4}{*}{$\begin{array}{l}\text { Phase II } \\
\text { [15] }\end{array}$} & $400 \mathrm{mg}$ BID & nausea & $64 \%$ & $2 \%$ \\
\hline & $n=64$ (OvCa) & fatigue & $59 \%$ & $11 \%$ \\
\hline & $\mathrm{n}=26(\mathrm{BCa})$ & loss of appetite & $34 \%$ & $2 \%$ \\
\hline & & diarrhoea & $19 \%$ & $5 \%$ \\
\hline \multirow{19}{*}{$\begin{array}{l}\text { Phase II } \\
{[16]}\end{array}$} & 400 mg BID & nausea & $72 \%$ & $6 \%$ \\
\hline & $\mathrm{n}=32$ & fatigue & $56 \%$ & $9 \%$ \\
\hline & & abdominal pain & $25 \%$ & $0 \%$ \\
\hline & & vomiting & $47 \%$ & $3 \%$ \\
\hline & & constipation & $16 \%$ & $0 \%$ \\
\hline & & diarrhoea & $38 \%$ & $0 \%$ \\
\hline & & asthenia & $34 \%$ & $0 \%$ \\
\hline & & (muscle weakness) & & \\
\hline & & urinary tract infection & $34 \%$ & $0 \%$ \\
\hline & & anaemia & $19 \%$ & $13 \%$ \\
\hline & $200 \mathrm{mg}$ BID & nausea & $56 \%$ & $3 \%$ \\
\hline & $\mathrm{n}=32$ & fatigue & $38 \%$ & $3 \%$ \\
\hline & & abdominal pain & $31 \%$ & $6 \%$ \\
\hline & & vomiting & $34 \%$ & $0 \%$ \\
\hline & & constipation & $22 \%$ & $6 \%$ \\
\hline & & diarrhoea & $19 \%$ & $0 \%$ \\
\hline & & asthenia & $16 \%$ & $3 \%$ \\
\hline & & urinary tract infection & $16 \%$ & $0 \%$ \\
\hline & & anaemia & $6 \%$ & $6 \%$ \\
\hline \multirow{8}{*}{$\begin{array}{l}\text { Phase II } \\
\text { [17] }\end{array}$} & $400 \mathrm{mg}$ BID & nausea & $66 \%$ & $2 \%$ \\
\hline & $\mathrm{n}=136$ & fatigue & $42 \%$ & $7 \%$ \\
\hline & & vomiting & $29 \%$ & $2 \%$ \\
\hline & & diarrhoea & $21 \%$ & $2 \%$ \\
\hline & & abdominal pain & $16 \%$ & $1 \%$ \\
\hline & & anaemia & $12 \%$ & $5 \%$ \\
\hline & & asthenia & $11 \%$ & $1 \%$ \\
\hline & & back pain & $9 \%$ & $2 \%$ \\
\hline
\end{tabular}

BID: twice daily; OvCa: ovarian carcinoma; BCa: breast carcinoma

\section{Niraparib}

Niraparib (MK4827) is a selective PARP1 and PARP2 inhibitor whose antiproliferative effect was first shown in in-vitro trials on BRCA1 and BRCA2 deficient cancer cells. Its efficacy was also shown in an animal model on artificial BRCA1-deficient tumours [24]. A phase I dose-finding trial found a maximum tolerable dose of $300 \mathrm{mg}$ daily. Toxic effects such as gastrointestinal symptoms, fatigue, anaemia, thrombocytopenia and neutropenia occurred frequently but severity was mostly low. Of patients with BRCA-associated ovarian carcinoma $40 \%$ (8 out of 20) showed partial response (RECIST) [25]. The efficacy and tolerability of niraparib monotherapy for platinum-sensitive recurrent ovarian carcinoma are currently being tested in an international phase III trial (NOVA). Results of phase II and phase III trials on the clinical use of niraparib have not yet been published.

\section{Rucaparib}

Ihnen et al. [26] studied the effect of the PARP inhibitor rucaparib (CO-338, AG014699, PF-01367338) on 39 different ovarian carcinoma cell lines in-vitro. The antitumour action of rucaparib was not limited to BRCA-mutated cells alone but also shown in cells with low-level expression of HRR-associated genes. The most obvious synergistic effects were shown for the combination of rucaparib plus topotecan. The efficacy and tolerability of oral rucaparib monotherapy have been tested in clinical studies. In addition to good tolerability [27], antitumour effect has been shown among patients with ovarian and peritoneal carcinoma both in platinum-sensitive and platinum-resistant disease (total tumour follow-up rate $86 \%$ ) with doses between 40 to 500 mg rucaparib daily and $240 \mathrm{mg}$ rucaparib twice daily respectively [28]. There is also published data on rucaparib in combination with cytostatic drugs. The efficacy of rucaparib as maintenance therapy for platinumsensitive recurrent ovarian carcinoma is the focus of two current international trials (ARIEL2 und ARIEL3).

\section{Talazoparib (BMN 673)}

BMN 673 is a PARP inhibitor whose antitumour action - according to findings of in-vitro studies on HRR-deficient cells (BRCA1, $B R C A 2, P T E N$ gene defects) - is assumed to be 20 to 200 times stronger than the other PARP inhibitors (olaparib, rucaparib, veliparib) [29]. The first clinical data on the use of talazoparib as monotherapy support these findings: tumour response (RECIST and/or CA-125) was shown at BMN 673 doses of 100 to $1100 \mu \mathrm{g}$ daily in 11 out of 17 patients with BRCA-associated ovarian and peritoneal carcinoma [30]. The occurrence of thrombocytopenia was however dose limiting so that the maximum tolerated dose of BMN $673(1000 \mu \mathrm{g})$ was significantly lower than that of other PARP inhibitors. Further phase II clinical trials of talazoparib's efficacy in ovarian carcinoma as well as phase II and phase III trials of talazoparib for BRCA-associated breast carcinoma (ABRAZO, EMBRACA) are still at recruiting stage.

\section{Other PARP inhibitors}

In addition to those mentioned above numerous other wellknown PARP inhibitors have been tested in clinical trials or are currently being tested (e.g. AZD2461, CEP9722, A7016, E7449, INO-1001). The efficacy of these substances has not yet been tested for ovarian carcinoma or data is yet to be published.

\section{Combination Strategies}

$\nabla$

In addition to use as monotherapy, PARP inhibitors have shown promise when used in combination with other treatments. The following is a selection of possible therapeutic approaches:

- In combination with chemotherapy: The DNA repair blocking effects of PARP inhibitors cause cells to be more sensitive to DNA damaging substances and can also delay the development of resistance to chemotherapy. [31]. Oza et al. [32] studied the combination of olaparib wtih carboplatin/paclitaxel followed by olaparib maintenance therapy in patients with platinumsensitive recurrent serous ovarian carcinoma. The addition of olaparib to carboplatin/paclitaxel chemotherapy and as maintenance thereafter resulted in a significant increase in progression-free interval from 9.6 (arm B) to 12.2 months (arm A) (arm A: olaparib $2 \times 200 \mathrm{mg}$ daily, day 1-10 with paclitaxel $175 \mathrm{mg} / \mathrm{m}^{2}$ and carboplatin AUC6 on day 1, for 6 cycles at intervals of 21 days followed by olaparib maintenance therapy 
$2 \times 400 \mathrm{mg} / \mathrm{d}$ until tumour progression; arm B: paclitaxel $175 \mathrm{mg} / \mathrm{m}^{2}$ and carboplatin AUC6 on day 1, for 6 cycles at intervals of 21 days without maintenance therapy). Toxicity profiles of the two regimes were similar.

- In combination with PI3-kinase inhibitors: The PI3K/AKT/ mTOR signal pathway is critical for many cell functions such as growth, metabolism and the initiation of DNA translation. The inhibition of PI3-kinase with PI3K inhibitors is a particularly interesting potential treatment strategy for ovarian carcinoma, since up to $70 \%$ of these tumours show overactivity of this pathway. Promising preclinical data have been published for the combination of PARP inhibitors with PI3K inhibitors [33]. The combination of olaparib and the PI3K inhibitor BKM120 for triple negative breast carcinoma and high-grade serous ovarian carcinoma (NCT01623349) is the subject of a current phase I trial that is still in the recruiting phase.

- In combination with angiogenesis inhibitors: Preclinical trials have provided evidence of hypoxia-mediated, reduced expression of proteins involved in DNA repair via the HRR pathway. A hypoxic environment is also known to increase the sensitivity of cells to PARP inhibitors [34-36]. Combinations of olaparib with bevacizumab [37] and cediranib [38] have been studied in clinical trials. In a phase II trial Liu et al. [39] showed that the "chemotherapy-free" combination of olaparib with cediranib clearly improved progression-free survival rate in platinum-sensitive recurrent ovarian carcinoma compared to olaparib monotherapy (PFS 17.7 months vs. 9.0 months respectively), although from the outset patients in both groups received no chemotherapy during recurrence. A phase III trial of the same combination strategy is planned [40].

\section{Future Prospects}

$\nabla$

The treatment of recurrent ovarian carcinoma remains a major challenge to clinicians. Since the disease in this form is incurable treatment is aimed at achieving a compromise between antitumour effect and a reasonable degree of reduced bodily reserves and quality of life. The fundamental treatment strategies target the platinum-free interval and are governed by differing tumour sensitivities to previous platinum-based chemotherapy. Results of all trials to date allow the conclusion that the various members of the PARP inhibitor drug class have clinically meaningful antitumour effects especially in high-grade serous platinum-sensitive ovarian carcinoma. With its licensing for treatment of platinumsensitive BRCA-mutated ovarian carcinoma, olaparib is the first PARP inhibitor to become part of the gynaecological-oncological treatment spectrum. This innovative treatment approach is a further step towards improved individualisation and the establishment of personalised, goal-directed therapy in clinical practice. This is conditional on a new level of clinical understanding of tumour complexity as well as molecular genetic evidence of disturbed DNA repair caused by BRCA mutations, both somatic and germ line. An exact genetic characterisation of tumours should thus be performed early on in tumour management. To achieve this prompt analysis of somatic and germ line mutations in patients with ovarian carcinoma the promotion of efficient organisational structures is necessary.

\section{Acknowledgements}

$\nabla$

We thank AstraZeneca for their kind support.

\section{Conflict of interest}

$\nabla$

Jalid Sehouli received honoraria for the participation in the following Advisory Boards: AstraZeneca, Pfizer, MSD, PharmaMar. The other authors declare no conflict of interest.

\section{References}

1 Robert Koch-Institut; Gesellschaft der epidemiologischen Krebsregister in Deutschland e.V., Hrsg. Krebs in Deutschland 2009/2010. 9. Ausgabe. Berlin: 2013

2 Marchetti C, Imperiale L, Gasparri ML et al. Olaparib, PARP1 inhibitor in ovarian cancer. Expert Opin Investig Drugs 2012; 21: 1575-1584

3 Antoniou A, Pharoah PD, Narod S et al. Average risks of breast and ovarian cancer associated with BRCA1 or BRCA2 mutations detected in case Series unselected for family history: a combined analysis of 22 studies. Am J Hum Genet 2003; 72: 1117-1130

4 Bolton KL, Chenevix-Trench G, Goh C et al. Association between BRCA1 and BRCA2 mutations and survival in women with invasive epithelial ovarian cancer. JAMA 2012; 307: 382-390

5 The Cancer Genome Atlas Research Network. Integrated genomic analyses of ovarian carcinoma. Nature 2011; 474: 609-615

6 Ledermann J, Harter P, Gourley C et al. Olaparib maintenance therapy in patients with platinum-sensitive relapsed serous ovarian cancer: a preplanned retrospective analysis of outcomes by BRCA status in a randomised phase 2 trial. Lancet Oncol 2014; 15: 852-861

7 Rouleau M, Patel A, Hendzel MJ et al. PARP inhibition: PARP1 and beyond. Nat Rev Cancer 2010; 10: 293-301

8 Do K, Cehn AP. Molecular pathways: targeting PARP in cancer treatment. Clin Cancer Res 2012; 19: 977-984

9 Lord CJ, Ashworth A. The DNA damage response and cancer therapy. Nature 2012; 481: 287-294

10 Patel AG, Sarkaria JN, Kaufmann SH. Nonhomologous end joining drives poly(ADP-ribose) polymerase (PARP) inhibitor lethality in homologous recombination-deficient cells. Proc Natl Acad Sci U S A 2011; 108: 3406-3411

11 Murai J, Huang SY, Das BB et al. Trapping of PARP1 and PARP2 by Clinical PARP Inhibitors. Cancer Res 2012; 72: 5588-5599

12 Mateo J, Ong M, Tan DS et al. Appraising iniparib, the PARP inhibitor that never was-what must we learn? Nat Rev Clin Oncol 2013; 10 : 688-696

13 Fong PC, Yap TA, Boss DS et al. Poly(ADP)-ribose polymerase inhibition: frequent durable responses in BRCA carrier ovarian cancer correlating with platinum-free interval. J Clin Oncol 2010; 28: 2512-2519

14 Audeh MW, Carmichael J, Penson RT et al. Oral poly(ADP-ribose) polymerase inhibitor olaparib in patients with BRCA1 or BRCA2 mutations and recurrent ovarian cancer: a proof-of-concept trial. Lancet 2010; 376: $245-251$

15 Gelmon KA, Tischkowitz M, Mackay $H$ et al. Olaparib in patients with recurrent high-grade serous or poorly differentiated ovarian carcinoma or triple-negative breast cancer: a phase 2, multicentre, open-label, non-randomised study. Lancet Oncol 2011; 12: 852-861

16 Kaye SB, Lubinski J, Matulonis U et al. Phase II, open-label, randomized, multicenter study comparing the efficacy and safety of olaparib, a poly (ADP-ribose) polymerase inhibitor, and pegylated liposomal doxorubicin in patients with BRCA1 or BRCA2 mutations and recurrent ovarian cancer. J Clin Oncol 2012; 30: 372-379

17 Ledermann J, Harter P, Gourley C et al. Olaparib maintenance therapy in platinum-sensitive relapsed ovarian cancer. N Engl J Med 2012; 366: 1382-1392

18 Fong PC, Boss DS, Yap TA et al. Inhibition of poly(ADP-ribose) polymerase in tumors from BRCA mutation carriers. N Engl J Med 2009; 361: 123-134

19 Kummar S, Kinders R, Gutierrez ME et al. Phase 0 clinical trial of the poly (ADP-ribose) polymerase inhibitor ABT-888 in patients with advanced malignancies. J Clin Oncol 2009; 27: 2705-2711 
20 Kummar S, Ji J, Morgan R et al. A phase I study of veliparib in combination with metronomic cyclophosphamide in adults with refractory solid tumors and lymphomas. Clin Cancer Res 2012; 18: 1726-1734

21 EMCC. Veliparib plus temozolomide in metastatic melanoma trends toward increased PFS but results are not statistically significant. Oncology (Williston Park) 2011; 25: 1213, 1232

22 Kummar S, Chen A, Ji J et al. Phase I study of PARP inhibitor ABT-888 in combination with topotecan in adults with refractory solid tumors and lymphomas. Cancer Res 2011; 71: 5626-5634

23 Coleman RL, Sill M, Aghajanian C et al. A phase II evaluation of the potent, highly selective PARP inhibitor veliparib in the treatment of persistent or recurrent epithelial ovarian, fallopian tube, or primary peritoneal cancer in patients who carry a germline BRCA1 or BRCA2 mutation. SGO Annual Meeting. Abstr. 136; presented March 25, 2014

24 Jones P, Altamura S, Boueres J et al. Discovery of 2-\{4-[(3 S)-piperidin-3yl]phenyl $\}-2 \mathrm{H}$-indazole-7-carboxamide (MK-4827): a novel oral poly (ADP-ribose)polymerase (PARP) inhibitor efficacious in BRCA-1 and -2 mutant tumors. J Med Chem 2009; 52: 7170-7185

25 Sandhu SK, Schelman WR, Wilding G et al. The poly(ADP-ribose) polymerase inhibitor niraparib (MK4827) in BRCA mutation carriers and patients with sporadic cancer: a phase 1 dose-escalation trial. Lancet Oncol 2014; 14: 882-892

26 Ihnen $M, z u$ Eulenburg C, Kolarova T et al. Therapeutic potential of the poly(ADP-ribose) polymerase inhibitor rucaparib for the treatment of sporadic human ovarian cancer. Mol Cancer Ther 2013; 12: 1002-1015

27 Kristeleit RS, Shapiro G, LoRusso Pet al. A phase I dose escalation and PK study of continuous oral rucaparib in patients with advanced solid tumors. J Clin Oncol 2013; 31 (Suppl.): Abstr. 2585

28 Kristeleit RS, Burris HA, LoRusso P et al. Phase 1/2 study of oral rucaparib: final phase 1 results. J Clin Oncol 2014; 32 (Suppl.): Abstr. 2573

29 Shen Y, Rehman FL, Feng $Y$ et al. BMN 673, a novel and highly potent PARP1/2 inhibitor for the treatment of human cancers with DNA repair deficiency. Clin Cancer Res 2013; 19: 5003-5015

30 DeBono JS, Mina LA, Gonzalez M et al. First-in-human trial of novel oral PARP inhibitor BMN 673 in patients with solid tumors. J Clin Oncol 2013; 31 (Suppl.): Abstr. 2580
31 Reinbolt RE, Hays JL. The role of PARP inhibitors in the treatment of gynecologic malignancies. Front Oncol 2013; 3: 237

32 Oza AM, Cibula D, Oaknin A et al. Olaparib plus paclitaxel plus carboplatin $(\mathrm{P} / \mathrm{C})$ followed by olaparib maintenance treatment in patients (pts) with platinum-sensitive recurrent serous ovarian cancer (PSR SOC): a randomized, open-label phase II study. J Clin Oncol 2012; 30 (Suppl.): Abstr. 5001

33 Juvekar A, Burga LN, Hu H et al. Combining a PI3K inhibitor with a PARP inhibitor provides an effective therapy for BRCA1-related breast cancer. Cancer Discov 2012; 2: 1048-1063

34 Bindra RS, Schaffer PJ, Meng A et al. Down-regulation of Rad51 and decreased homologous recombination in hypoxic cancer cells. Mol Cell Biol 2004; 24: 8504-8518

35 Bindra RS, Gibson SL, Meng A et al. Hypoxia-induced down-regulation of BRCA1 expression by E2Fs. Cancer Res 2005; 65: 11597-11604

36 Chan N, Pires IM, Bencokova Z et al. Contextual synthetic lethality of cancer cell kill based on the tumor microenvironment. Cancer Res 2010; 70: 8045-8054

37 Dean E, Middleton MR, Pwint $T$ et al. Phase I study to assess the safety and tolerability of olaparib in combination with bevacizumab in patients with advanced solid tumours. Br J Cancer 2012; 106: 468-474

38 Liu JF, Tolaney SM, Birrer M et al. A phase 1 trial of the poly(ADP-ribose) polymerase inhibitor olaparib (AZD2281) in combination with the anti-angiogenic cediranib (AZD2171) in recurrent epithelial ovarian or triple-negative breast cancer. Eur J Cancer 2013; 49: 2972-2978

39 Liu JF, Barry WT, Birrer $M$ et al. Combination cediranib and olaparib versus olaparib alone for women with recurrent platinum-sensitive ovarian cancer: a randomised phase 2 study. Lancet Oncol 2014; 15: 1207-1214

40 Liu JF, Barry WT, Birrer $M$ et al. A randomized phase 2 trial comparing efficacy of the combination of the PARP inhibitor olaparib and the antiangiogenic cediranib against olaparib alone in recurrent platinumsensitive ovarian cancer. ASCO Annual Meeting. Abstr. LBA5500; presented May 31, 2014 